\title{
Cortical Synaptic Inhibition Declines during Auditory Learning
}

\author{
Emma C. Sarro, Gardiner von Trapp, Todd M. Mowery, Vibhakar C. Kotak, and Dan H. Sanes \\ Center for Neural Science, New York University, New York, New York 10003
}

\begin{abstract}
Auditory learning is associated with an enhanced representation of acoustic cues in primary auditory cortex, and modulation of inhibitory strength is causally involved in learning. If this inhibitory plasticity is associated with task learning and improvement, its expression should emerge and persist until task proficiency is achieved. We tested this idea by measuring changes to cortical inhibitory synaptic transmission as adult gerbils progressed through the process of associative learning and perceptual improvement. Using either of two procedures, aversive or appetitive conditioning, animals were trained to detect amplitude-modulated noise and then tested daily. Following each training session, a thalamocortical brain slice was generated, and inhibitory synaptic properties were recorded from layer $2 / 3$ pyramidal neurons. Initial associative learning was accompanied by a profound reduction in the amplitude of spontaneous IPSCs (sIPSCs). However, sIPSC amplitude returned to control levels when animals reached asymptotic behavioral performance. In contrast, paired-pulse ratios decreased in trained animals as well as in control animals that experienced unpaired conditioned and unconditioned stimuli. This latter observation suggests that inhibitory release properties are modified during behavioral conditioning, even when an association between the sound and reinforcement cannot occur. These results suggest that associative learning is accompanied by a reduction of postsynaptic inhibitory strength that persists for several days during learning and perceptual improvement.
\end{abstract}

Key words: associative learning; auditory cortex; inhibition; synaptic plasticity

\section{Introduction}

The representation of sound in auditory cortex can be modified by both chronic environmental conditions and learning (for review, see Keuroghlian and Knudsen, 2007; Sanes and Bao, 2009; de Villers-Sidani and Merzenich, 2011; Schreiner and Polley, 2014). For example, learning to detect a spectral cue or discriminate a spectral cue from among other cue causes (1) cortical single-neuron receptive fields to shift rapidly and persistently toward the conditioned frequency, and (2) representation of relevant frequencies to expand (Edeline et al., 1993; Recanzone et al., 1993; Blake et al., 2002; Keeling et al., 2008). In fact, the magnitude of reorganization is correlated with both magnitude of learning, as well as resistance to extinction (Rutkowski and Weinberger, 2005; Bieszczad and Weinberger, 2010). Modification of functional properties is not restricted to sound frequency. Learning can also lead to altered temporal response properties or sound-level tuning to favor the features of salient sounds (Bao et al., 2004; Polley et al., 2004). However, learning-induced alterations of the cortical sensory representation can dissipate as ani-

\footnotetext{
Received Sept. 30, 2014; revised March 11, 2015; accepted March 12, 2015.

Author contributions: E.C.S., G.v.T., T.M.M., V.C.K., and D.H.S. designed research; E.C.S., G.v.T., T.M.M., V.C.K., and D.H.S. performed research; E.C.S. contributed unpublished reagents/analytic tools; E.C.S., G.v.T., T.M.M., V.C.K., and D.H.S. analyzed data; E.C.S., G.v.T., T.M.M., V.C.K., and D.H.S. wrote the paper.

This work was supported by NIH Grant DC011284. We thank Ramanjot Kang and Anne Takesian for their contributions to this project.

The authors declare no competing financial interests.

Correspondence should be addressed to Emma C. Sarro, 4 Washington Place, Room 809, New York University, New York, NY 10003. E-mail: emma.sarro@nyumc.org.

DOI:10.1523/JNEUROSCI.4051-14.2015

Copyright $\odot 2015$ the authors $\quad 0270-6474 / 15 / 356318-08 \$ 15.00 / 0$
}

mals continue to practice a task (Molina-Luna et al., 2008; Yotsumoto et al., 2008; Takahashi et al., 2010; Reed et al., 2011), suggesting that the changes underlying learning can shift to other loci when certain training regimens are used. Thus, auditory learning is accompanied by modifications to the representation of acoustic cues in primary auditory cortex, which may facilitate behavioral sensitivity to the conditioned stimulus.

Disinhibition or the reduction of inhibitory synaptic gain and the associated increase in excitability is one cellular mechanism that may facilitate long-term modification to sensory cortex processing. In fact, the ability to induce or facilitate a neural substrate of learning, long-term potentiation, is known to depend on reducing inhibitory drive (Wigström and Gustafsson, 1986; Steward et al., 1990; Mott and Lewis, 1991; Brucato et al., 1996; Hsu et al., 1999; Ormond and Woodin, 2011). In the auditory system, the experience-dependent plasticity that occurs during classical conditioning is associated with an enhancement of excitation within the auditory cortex (Blake et al., 2006). Consistent with this finding, disinhibition in the auditory cortex is necessary for a simple form of associative learning (Letzkus et al., 2011). We predicted that, if inhibitory plasticity is associated with task learning, then the expression of inhibitory plasticity would emerge and persist until task proficiency was achieved, regardless of the training procedure.

To examine whether adjustments to cortical GABAergic transmission accompany associative learning, we measured spontaneous $\mathrm{GABA}_{\mathrm{A}}$ receptor-mediated synaptic currents in auditory cortex brain slices obtained from gerbils undergoing daily auditory training. Animals were trained to detect an amplitudemodulated noise, using either an aversive or an appetitive proce- 
A

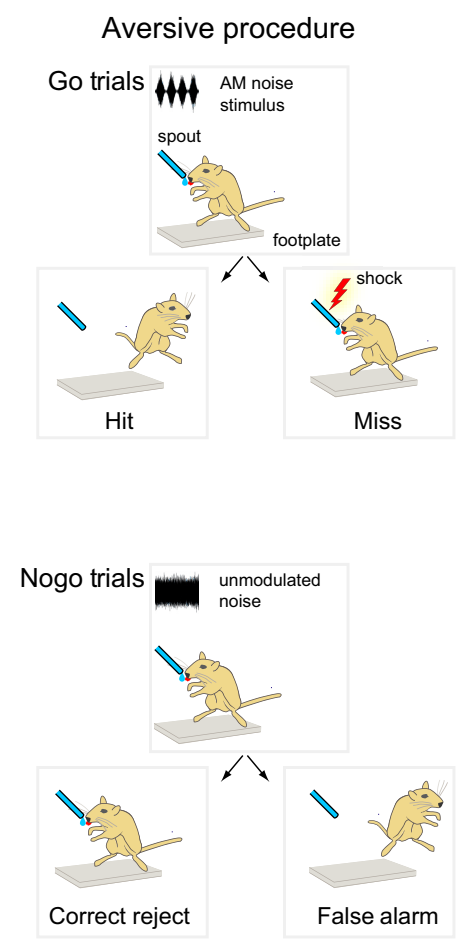

B
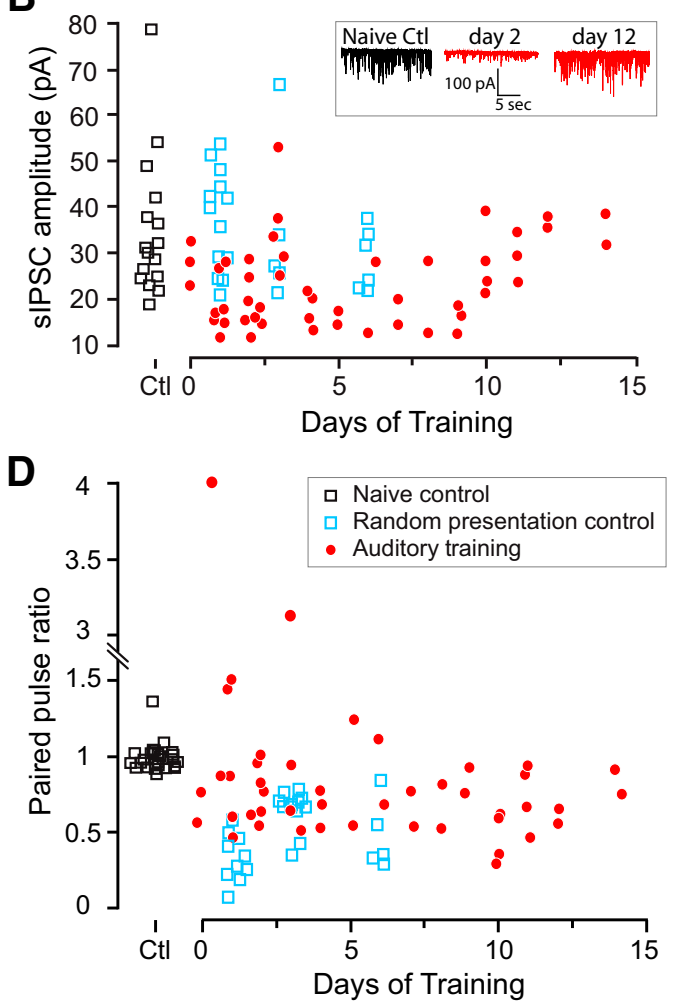

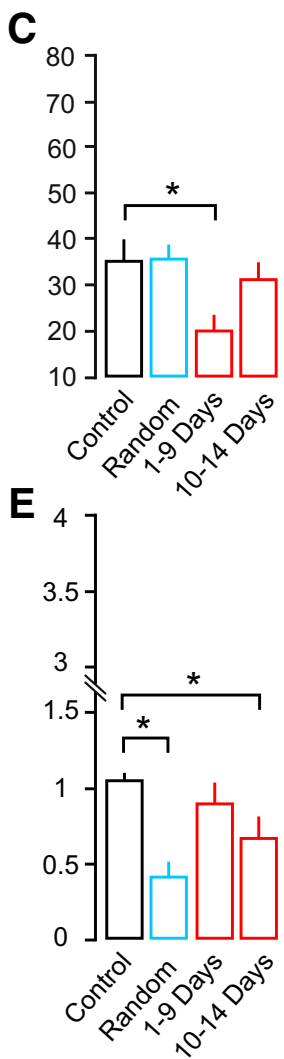

Figure 1. Associative learning and inhibitory synaptic measures during aversive conditioning. $\boldsymbol{A}$, Schematics show the possible behavioral responses to both kinds of trials (left: Go and Nogo trials). Behavioral responses (right) could result in a "hit," "miss," "false alarm," or "correct reject." B, sIPSC amplitude (in picoamperes) as a function of the days that each animal received aversive training. Each data point represents one cell. Cells from naive control animals (black squares) are plotted against cells from aversively trained animals (red circles) and those from animals with unpaired aversive training (light blue squares). Inset, Example traces of sIPSCs taken from a naive animal (black, left), from a trained animal during the initial phase of associative learning (red, middle; day 2), and from a trained animal during the later phase of associative learning (red, right; day 12). C, sIPSC amplitudes are averaged by training period. Average sIPSC amplitude from naive control animals are compared with the average sIPSC amplitude from all animals with unpaired aversive conditioning, those animals with aversive conditioning and training for $1-9 \mathrm{~d}$ and those animals with aversive conditioning for $10-14 \mathrm{~d}$. $\boldsymbol{D}, \boldsymbol{E}$, PPRs for the above named animals as a function of days of training $(\boldsymbol{D})$ as well as averaged by animal group $(\boldsymbol{E})$. Error bars indicate $S E M$; * $p<$ 0.05 .

dure. Auditory cortex brain slices were obtained on sequential days, immediately following each training session. Both presynaptic and postsynaptic measures of inhibitory function were recorded to determine whether synaptic adjustments were associated with learning, and whether they were specific to a particular training procedure. The results showed a decrease in IPSC amplitude that coincided with the onset of associative learning in animals with auditory training, but not in control animals. In contrast, the paired-pulse ratio (PPR) decreased both in animals with auditory training and in controls. These results suggest that a transient decrease in inhibitory gain permit the modification of stimulus representation that accompanies learning.

\section{Materials and Methods}

Gerbil (Meriones unguiculatus) pups were weaned from commercial breeding pairs (Charles River). Males and females were caged separately and maintained in a $12 \mathrm{~h} \mathrm{light/dark} \mathrm{cycle.} \mathrm{Animals} \mathrm{were} \mathrm{trained} \mathrm{on} \mathrm{one} \mathrm{of}$ two auditory tasks: either a conditioned-avoidance task or appetitive task (both described in detail below). All procedures related to the maintenance and uses of animals were in accordance with the Institutional Animal \& Use Committee Handbook and approved by the University Animal Welfare Committee at New York University.

\section{Behavior: aversive conditioning}

Animals were trained on a Go-Nogo conditioned-avoidance procedure to detect amplitude modulation (Heffner and Heffner, 1995; Heffner et al., 2006; Kelly et al., 2006; Sarro and Sanes, 2010, 2011). Since we were interested in the physiological changes that may occur in the same animals over the course of associative learning, we recorded cells from animals that had an increasingly greater number of training days.

Apparatus. Gerbils were placed in a small plastic cage in a soundisolation booth (Gretch-Ken Industries) and observed from a separate room via a closed-circuit monitor. When the animal contacted both the plate and spout, a circuit was completed that initiated water delivery via a syringe pump (New Era Pump Systems). A personal computer, connected to a digital input/output interface (TDT RZ6, Tucker-Davis Technologies) controlled the timing of the acoustic stimuli, water delivery $(0.3$ $\mathrm{ml} / \mathrm{min}$ ), and a small current delivered through a metal lick spout. Auditory stimuli were generated by a Tucker-Davis Technologies system and delivered via a calibrated tweeter (KEF Electronics) positioned $1 \mathrm{~m}$ in front of the test cage at $0^{\circ}$ elevation. Sound level was measured with a spectrum analyzer (3550, Bruel \& Kjaer) via a one-quarter inch free-field condenser microphone positioned at the head location when in contact with the lick spout. The metal lick spout was similar in appearance to that within the home cage (Fig. $1 A$ ).

Procedural training. Animals were placed on controlled water access and learned to obtain water from the lick spout in the presence of a continuous unmodulated noise stimulus, which played continuously during each behavioral session. Animals were then trained to suppress their drinking behavior and to withdraw from the lick spout when the continuous noise signal was amplitude modulated at $5 \mathrm{~Hz}$ (warning signal). To train the withdrawal response, a low AC current (0.5-1.0 mA, $0.3 \mathrm{~s}$; Lafayette Instruments) was delivered through the lick spout immediately after the warning signal. Since animals display large between- 
subject variability in pain sensitivity (Mogil, 1999; Wasner and Brock, 2008; Nielsen et al., 2009), we adjusted the shock level for each animal to reliably produce withdrawal from the spout, but not so great as to dissuade an animal from approaching the spout on subsequent trials. The animals' behavior was monitored constantly to ensure that the level was set correctly. To initially train animals on the task, warning trials $(100 \%$ modulation depth) were presented until performance reached a criterion of $\geq 70 \%$ correct over 10 consecutive trials. Behavioral trials were cued by the animal's contact with the waterspout. Thus, animals had to be in contact with the waterspout for a specific amount of time before the modulation of sound initiated. Once they reached criterion on the conditioned-avoidance procedure, animals received training that consisted of the presentation of 5 amplitude-modulated depths $\geq 5$ times in descending order, bracketing each animal's detection threshold from the previous day's performance. This type of training session continued daily until brain-slice assessments were made. It is possible that animals could have learned to perform the task by attending to an acoustic cue other than amplitude modulation (e.g., short-term change in average level), but the experimental design and interpretations depend on learning per se, rather than the learning of a specific cue.

Behavioral trial structure and auditory stimuli. A series of warning trials were interleaved with a variable number of safe trials. Each warning or safe trial was $2.5 \mathrm{~s}$ long. The sound level remained constant ( $45 \mathrm{~dB}$ equivalent SPL) throughout all intervals to exclude the use of an energy cue. The noise stimulus was broadband (measured as an rms), with a $25 \mathrm{~dB}$ roll-off at $3.5 \mathrm{kHz}$ and a $25 \mathrm{~dB}$ roll-off at $20 \mathrm{kHz}$. Each warning trial contained $1.2 \mathrm{~s}$ of unmodulated noise during the pretrial interval, and the spout was monitored for contact during the final $0.5 \mathrm{~s}$ of this interval. The trial proceeded only if the animal remained in contact with the spout for $>0.25 \mathrm{~ms}$ during this interval. The warning stimulus was $1.0 \mathrm{~s}$ of sinusoidally amplitude-modulated noise at a modulation frequency of $5 \mathrm{~Hz}$, and the depth of amplitude modulation was varied. Warning stimuli were followed immediately by an aversive unconditioned stimulus $(0.3 \mathrm{~s}$ electrical current delivered via the lick spout). To determine whether the animal detected the warning stimulus, contact with the spout was monitored during the final $0.1 \mathrm{~s}$ of the warning stimulus. A contact time of $<50 \mathrm{~ms}$ was scored as a hit and a contact time of $>50 \mathrm{~ms}$ was scored as a miss. For safe trials, a contact time of $<50 \mathrm{~ms}$ was scored as a false alarm and a contact time of $>50 \mathrm{~ms}$ was scored as a correct rejection (Fig. $1 \mathrm{~A}$ ). Warning trials were interleaved with 2-4 safe trials, randomized to avoid temporal conditioning. We also ran a control group that received random presentation of the amplitude-modulated stimulus interspersed with shock delivery such that animals were unable to form a temporal association between the auditory stimulus with the unconditioned stimulus (i.e., shock).

Data analysis. A performance metric was calculated by performing a $z$-transform of both false-alarm and hit values: $d^{\prime}=z_{\text {false alarm }}-z_{\text {hit }}$. The final value was obtained for $z$ scores that corresponded to the right-tail $p$ values, or the positive difference between the two respective $z$ scores (Swets, 1973; Yanz, 1984), and was calculated for each amplitudemodulated depth. Thresholds were defined as the amplitude-modulated depth at which performance reached a $d^{\prime}=1$. Only sessions in which an animal performed $\geq 25$ trials were included in the analysis.

Experimental groups. The trained animals and cells were as follows: postnatal day (P) 25-P35: $n=13$ animals; $n=31$ cells; adults: $n=9$ animals; $n=19$ cells; when pooled: $\mathrm{n}=22$ animals; $n=50$ cells. Animals were trained as described above on the conditioned-avoidance task. Brain slices were obtained within $3 \mathrm{~h}$ of a training session, and animals that were recorded later in the protocol had more cumulative training sessions. The study was initially designed to determine whether there was an effect of age. We were motivated, in part, by previous behavioral results indicating a difference between juvenile and adult learning (Sarro and Sanes, 2010,2011). However, we found no significant difference in spontaneous IPSC (sIPSC) amplitude or PPR value as a function of age. Thus, sIPSC amplitude at days 1-9 of training was nearly identical for adult-trained animals $(21.4 \pm 2.1 \mathrm{pA})$ and juvenile-trained animals $\left(21.5 \pm 1.9\right.$ pA; ANOVA: $\left.F_{(1,36)}=0.004, p=1.0\right)$. Similarly, PPR value did not differ significantly (ANOVA: $F_{(1,33)}=1.6, p=0.2$ ). Nor was there a difference between juvenile-trained and adult-trained animals during the later phase of training, from days 10-14 (sIPSC amplitude: $F_{(1,9)}=0.002, p=1.0$; PPR value: $\left.F_{(1,10)}=1.7, p=0.2\right)$. Thus, juvenile and adult animals were combined for all subsequent analyses.

Animals categorized as unpaired control (adults, $n=4$ animals, $n=24$ cells) were exposed to the training environment as described above but presentations of both auditory stimuli and shock were delivered randomly.

Animals categorized as naive control (adults; $n=9$ animals; $n=28$ cells for PPR data; $n=4$ animals, $n=16$ cells for sIPSC amplitude measurements) were not exposed to the training environment or auditory stimuli before obtaining brain slices.

\section{Behavior: appetitive conditioning}

Separate groups of animals were trained using a Go-Nogo procedure to detect modulations in amplitude using a positive-reinforcement procedure (Buran et al., 2014). Briefly, each animal was trained to initiate a trial upon presentation of a Go stimulus (amplitude-modulated noise) by placing its nose in a nose port and approach a water spout. They were also trained to repoke upon presentation of a Nogo stimulus (unmodulated noise; Fig. $2 A$ ).

Apparatus. All aspects of the testing apparatus were the same as with the aversive-conditioning task with the following differences. A small nose port was present in the testing cage on the side opposite the water spout. Animals were rewarded with $25 \mu$ l of water when they approached the water spout on a Go trial. Auditory stimuli were delivered from a speaker $1 \mathrm{~m}$ above the test cage.

Procedural training. Animals were placed on controlled water access and learned to obtain water from a spout upon introduction to the test cage. Initially, when animals received water, the Go stimulus (amplitudemodulated noise) was delivered. Animals were then trained to respond to the Go stimulus by approaching the spout when the Go signal was presented. Once all animals responded strongly to Go presentation, the nose port was placed in the testing cage. In one training session, animals were able to discover and reliably initiate Go trials independently by placing their nose in the port. On the initial day of nose-port training, only Go trials (100\% modulation depth) were presented. Once behavioral trials were reliably cued by the animal maintaining position in the nose port, Nogo trials were introduced. On each training session following the introduction of the Nogo stimulus, brain-slice assessments were made within 30-60 min following training.

Behavioral trial structure and auditory stimuli. The same noise stimulus used in the aversive task was used in the appetitive task. Go trials employed sinusoidally amplitude-modulated noise at a modulation frequency of $5 \mathrm{~Hz}$, and the depth of amplitude modulation was kept at $100 \%$. False-alarm trials (contact with spout when Nogo stimulus was presented) were not rewarded. To determine whether the animal detected the Go stimulus, contact with the spout was monitored. For Nogo trials, contact with the water spout constituted a false alarm and a repoke or no response with a $5 \mathrm{~s}$ window was scored as a correct rejection (Fig. $2 A)$. Presentation of Go and Nogo trials were randomized to avoid animals developing possible predictive strategies.

Experimental groups. Animals in the trained category were as follows: P50-P95 (average P72), $n=39$ cells, $n=9$ animals. These animals were trained as described above. Brain slices were obtained from animals during the course of the training period.

\section{Brain-slice recordings}

Preparation and recordings were done in a manner previously reported to compare our findings with many of our previous studies (Kotak et al., 2008; Takesian et al., 2012). The brain was sectioned perihorizontally at $15-25^{\circ}$ to preserve the ventral medial geniculate (MGv) and its ascending pathways to the auditory cortex (ACx). The slices were incubated in ACSF at $32^{\circ} \mathrm{C}$ for $30-45 \mathrm{~min}$, kept at room temperature for $\sim 45 \mathrm{~min}$, and transferred to a recording chamber continuously superfused $(\sim 3$ $\mathrm{ml} / \mathrm{min}$ ) with ACSF at $32 \pm 1^{\circ} \mathrm{C}$. The ACSF contained the following (in $\mathrm{mm}$ ): $125 \mathrm{NaCl}, 4 \mathrm{KCl}, 1.2 \mathrm{KH}_{2} \mathrm{PO}_{4}, 1.3 \mathrm{MgSO}_{4}, 24 \mathrm{NaHCO}_{3}, 15$ glucose, $2.4 \mathrm{CaCl}_{2}$, and $0.4 \mathrm{~L}$-ascorbic acid, pH 7.3 when bubbled with $95 \% \mathrm{O}_{2}$ / $5 \% \mathrm{CO}_{2}$. Whole-cell recording were obtained from the thalamorecipient $\mathrm{ACx}$ previously validated by extracellular field activity recorded in re- 
A

Appetitive auditory task
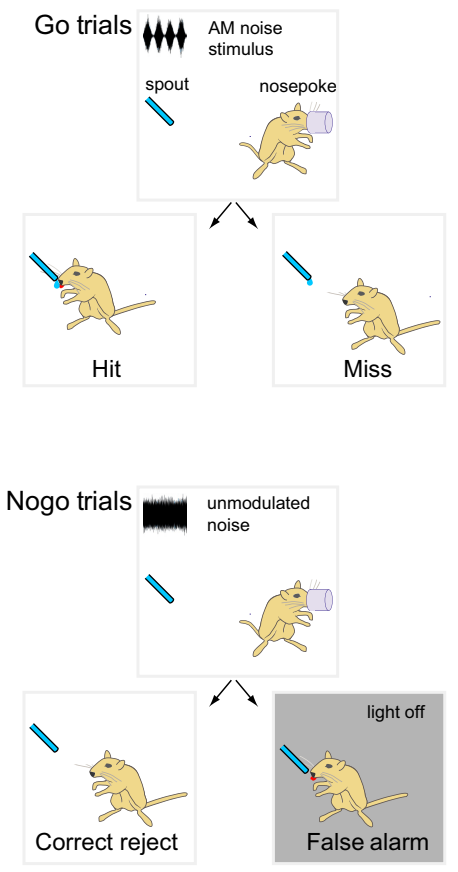

B
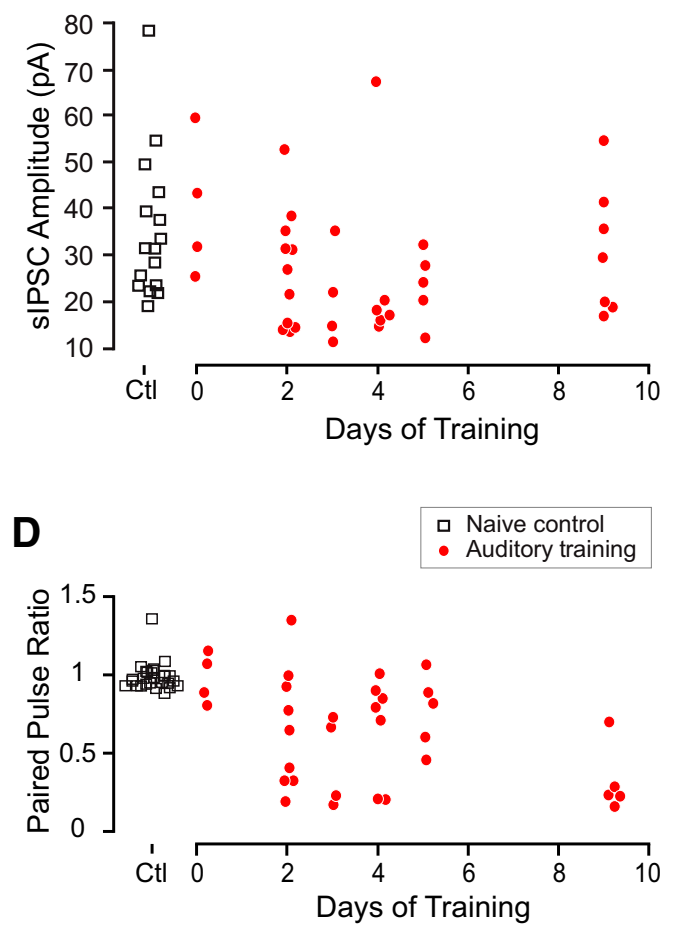

C

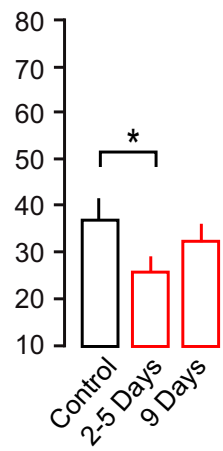

$\mathbf{E}$

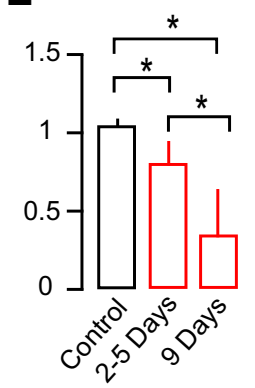

Figure 2. Associative learning and inhibitory synaptic measures during appetitive conditioning. $A$, Schematics show the possible behavioral responses to both kinds of trials (left: Go and Nogo trials). Behavioral responses (right) could result in a "hit," "miss," "false alarm," or "correct reject." B, sIPSC amplitude (in picoamperes) as a function of the days that each animal received appetitive training. Each data point represents one cell. Cells from naive control animals (black squares) are plotted against cells from trained animals (red circles). C, sIPSC amplitudes are averaged by training period. Average sIPSC amplitude from naive control animals are compared with the average sIPSC amplitude from those animals with training for $2-5 \mathrm{~d}$ and those animals with training for $9 \mathrm{~d}$. $\boldsymbol{D}$, $\boldsymbol{E}$, PPRs for the above named animals as a function of days of training $(\boldsymbol{D})$ as well as averaged by animal group $(\boldsymbol{E})$. Error bars indicate SEM; ${ }^{*} p<0.05$.

sponse to MGv stimulation. Ionotropic glutamate receptor blockers, 6,7dinitroquinoxaline-2,3-dione (DNQX, $20 \mu \mathrm{M}$ ) and 2-amino-5 phosphonopentanoate (AP-5, $50 \mu \mathrm{M})$, were continuously bath applied with ACSF to isolate inhibitory currents.

Recording electrodes were made from borosilicate glass microcapillaries (outer diameter, $1.5 \mathrm{~mm}$ ) with a puller (P-97, Sutter Instruments). The internal recording solution contained the following (in $\mathrm{mM}$ ): 100 $\mathrm{KCl}, 40 \mathrm{~K}$-gluconate, $8 \mathrm{NaCl}, 10 \mathrm{HEPES}, 2 \mathrm{MgCl}_{2}$, 0.1 EGTA, $2 \mathrm{ATP}, 0.3$ GTP, and 5 lidocaine derivative QX-314, pH 7.2 with $\mathrm{KOH}$. The internal recording solution contained a relatively high chloride concentration, resulting in inward inhibitory currents at a holding potential of $-60 \mathrm{mV}$. The resistance of these electrodes filled with the internal solution was 5-12 $\mathrm{M} \Omega$. Access resistances were $15-40 \mathrm{M} \Omega$ and were compensated by $\sim 70 \%$. Layer $2 / 3$ pyramidal cells were identified by their characteristically shaped cell bodies under infrared differential interface contrast optics at $400 \times$. After breaking the $\geq 1 \mathrm{G} \Omega$ membrane patch, it was possible to immediately record a resting potential $(<50 \mathrm{mV})$ and an overshooting action potential before spikes were blocked to validate that cells were healthy. Recordings were then made using voltage clamp $\left(V_{\mathrm{HOLD}}=-60\right.$ $\mathrm{mV}$ ) after $5 \mathrm{~min}$ to allow steady-state blockade of sodium channels as well as diffusion of chloride. sIPSCs were recorded in the presence of ionotropic glutamate receptor blockers, which were added to the oxygenated superfusing ACSF 10 min after the continuous application of the DNQX (20 $\mu \mathrm{M}$; Sigma-Aldrich) and AP-5 (50 $\mu \mathrm{M}$; Tocris Cookson).

To obtain a PPR, two stimulus pulses $(100 \mu \mathrm{S})$ delivered via a stimulus isolation unit (model BSI-9501, Dagan) to a bipolar stimulating electrode placed on L4 were used. The stimulating electrode was fabricated from 0.004-inch-diameter Teflon-coated platinum wires (A-M Systems) inserted into a 2-inch-long double-barrel glass electrode. The exposed tip was $50.8 \mu \mathrm{m}$ in diameter. To determine the stimulus magnitude, incremental stimulus intensities were delivered at $0.05 \mathrm{~Hz}$ until an evoked IPSC was discernible from failures (Kotak et al., 2008). A stimulus magnitude of $20 \%$ above this threshold was chosen to avoid failures. At least
10 evoked IPSC sweeps were acquired at $0.01 \mathrm{~Hz}$. Here, PPR is defined as the ratio between the average IPSC amplitude evoked by the second stimulus pulse divided by the average IPSC amplitude evoked by the first stimulus pulse (IPSC2/IPSC1). A ratio of $>1$ represents facilitation. A ratio of $<1$ represents depression. Thus, comparisons of PPR in controls versus behaviorally trained animals would thus reveal whether training altered GABA release. Cells from all animals presented in this study were included in the statistical analysis. We acknowledge that the PPR provides an indirect measure of presynaptic release (Manabe et al., 1993; Dobrunz and Stevens, 1997).

Data were filtered at $5 \mathrm{kHz}$ and acquired at a sampling rate of $10 \mathrm{kHz}$ by a custom-designed IGOR (version 4.08, WaveMetrics) macro on a Macintosh platform called Slice (Apple). A second IGOR macro (Slice analysis) was used for off-line analysis. To identify events, this macro used a semiautomated procedure that used a threshold value based on the SD of the acquired trace. A minimum threshold of $-10 \mathrm{pA}$ was used to detect sIPSCs. All IPSC data are reported as mean pA \pm SEM. Cells from all animals presented in this study were included in the statistical analysis. Details on the acquisition and analysis of sIPSC amplitude and frequency, minimum-evoked IPSC amplitude, and PPR have been described previously (Takesian et al., 2010).

\section{Results}

To assess whether auditory cortex inhibitory synaptic properties were altered during the acquisition of an auditory task, gerbils were either trained to detect amplitude-modulated noise by pairing the amplitude-modulated stimulus with a mild shock (aversive conditioning) or with water reward (appetitive conditioning). Inhibitory synaptic properties were recorded from brain slices of animals immediately following daily training sessions. The first set of recordings were obtained within a few hours after completion of the first training session, during which animals failed to 
learn the task. Subsequent recordings were obtained daily and always within $1-3 \mathrm{~h}$ of the training session. Thus, brain slices obtained on the second day came from animals that were showing improvement on the task and had experienced two training sessions; slices obtained on the third day came from animals that had experienced three training sessions; and so forth. We also obtained these measures from a control group of animals in which amplitude-modulated stimuli and unconditioned stimuli (shock) were delivered randomly. For this control group, the total number of stimuli was chosen to match that experienced by the trained animals. The animals that did not experience a pairing of amplitude modulation and shock displayed no learning. Recordings were also compared with sIPSCs obtained from naive age-matched control gerbils.

Learning to perform the task was associated with a reduction in sIPSC amplitude. Figure $1 B, C$ plots the reduction in sIPSC amplitude as a function of day of training. Neurons that were recorded from animals trained with the aversive paradigm displayed a reduction in sIPSC amplitude during the first week of training, compared with naive control animals [Fig. 1C; ANOVA (all groups included): $F_{(1,3)}=11.4, p<0.0001$; naive control $(34.6 \pm 3.7 \mathrm{pA})$ vs aversive-trained days $1-9(19.7 \pm 2.0 \mathrm{pA}) ; t$ test: $\left.t_{(1,46)}=4.4, p<0.0001\right]$. However, additional training did not induce a further reduction in sIPSC amplitude (naive control vs aversive-trained days $10-14(31.2 \pm 3.8 \mathrm{pA}): t$ test: $t_{(1,25)}=$ $0.68, p=0.5$ ). Furthermore, no change in sIPSC amplitude was observed in neurons recorded from animals exposed to randomly presented amplitude modulation and shock [naive control vs random presentation control $(34.6 \pm 2.9 \mathrm{pA}): t$ test: $t_{(1,38)}=$ $0.005, p=1.0$; a post hoc Tukey's test revealed that sIPSC amplitude differed only within those animals during the first week of training at $p<0.05]$. The reduction in sIPSC amplitude occurred $\geq 1 \mathrm{~d}$ after the associative conditioning began, as cells from animals that were obtained immediately after the first conditioning session were not significantly different from those of control animals $\left(27.8 \pm 8.5 \mathrm{pA} ; t\right.$ test: $\left.t_{(1,17)}=0.73, p=0.47\right)$. The decrease in inhibitory strength was not associated with an average reduction in holding current, which would have indicated an increased leak conductance (naive control: $n=16,-39 \pm 30 \mathrm{pA}$; aversivetrained days 1-9: $n=31,64 \pm 22 \mathrm{pA}$; aversive-trained days $10-14: n=11,88 \pm 36 \mathrm{pA}$; random presentation: $n=24,35 \pm 25$ pA; ANOVA: $\left.F_{(3,78)}=0.62, p=0.6\right)$.

To determine whether aversive training influenced presynaptic release, paired-pulse protocol ( $80 \mathrm{~ms}$ interstimulus interval; Takesian et al., 2010) was obtained for each recorded neuron. A main effect of treatment group was observed (ANOVA: $F_{(1,3)}=$ $27.5, p<0.0001$ ), and a post hoc Tukey's test revealed significant differences $(p<0.05)$ between control cells and those from animals with unpaired conditioning, as well as those from cells in later stages of training (days 10-14). Notably, cells recorded from control animals with no explicit pairing of amplitude modulation and shock also displayed significantly diminished PPR values, compared with naive animals $\left(0.41 \pm 0.04 ; t\right.$ test: $t_{(1,46)}=13.2$, $p<0.0001)$. Furthermore, PPR was reduced primarily during a later stage of training (Fig. $1 D, E$ ). Thus, PPR values obtained from trained animals during the initial part of training were lower but not significantly different from those obtained from naive animals (naive control, $1.03 \pm 0.05$, vs aversive-trained days $1-9$, $0.89 \pm 0.05$; $t$ test: $\left.t_{(1,55)}=1.93, p=0.06\right)$. Neurons recorded from animals with longer durations of training displayed significantly diminished PPR values $\left(0.65 \pm 0.05\right.$; $t$ test: $t_{(1,38)}=6.82$, $p<0.0001)$. Thus, modifications to presynaptic release seemed to be dependent on being placed in the learning context, even when no learning occurred.

To determine whether alterations to inhibitory synaptic strength were specific to the aversive training paradigm, an appetitive procedure was used to train a separate group of animals to detect amplitude-modulated stimuli (see Materials and Methods). Neurons recorded from brain slices obtained within 1 hour of appetitive training displayed a decrease in sIPSC amplitudes, similar to that observed for the aversive procedure (Fig. $2 B$ ). The reduction in sIPSC amplitude occurred during the initial period of training, and further training did not induce a change [Fig. 2C; ANOVA: $F_{(1,2)}=3.9, p<0.05$; a post hoc Tukey's test revealed significant differences $(p<0.05)$ between control cells and those from animals in early stages of training; naive control $(34.6 \pm 3.7$ pA) vs appetitive-trained days $2-5(25.5 \pm 2.6 \mathrm{pA}): t$ test: $t_{(1,41)}=$ $2.75, p<0.01$; naive control vs appetitive-trained for $9 \mathrm{~d}(31.4 \pm$ $5.7 \mathrm{pA}): t$ test: $\left.t_{(1,21)}=0.47, p=0.6\right]$. The reduction in sIPSC amplitude occurred $\geq 1 \mathrm{~d}$ after the appetitive training began, as cells recorded from animals immediately after the first session did not differ significantly from cells recorded from naive controls $\left(40.2 \pm 7.6 \mathrm{pA}\right.$; $t$ test: $\left.t_{(1,18)}=0.65, p=0.5\right)$.

PPR was altered during the course of appetitive training, similar to that observed during aversive training [Fig. $2 D, E$; ANOVA: $F_{(1,2)}=28.3, p<0.0001$; a post hoc Tukey's test revealed significant differences $(p<0.05)$ between PPRs of control cells and those from animals in later stages of training]. However, PPR values declined during an early phase of conditioning, and continued within the later phase. Specifically, PPR values obtained from trained animals during the first week of training were lower than those of naive controls [naive control $(1.03 \pm 0.05)$ vs appetitive-trained days $2-5(0.64 \pm 0.05): t$ test: $t_{(1,52)}=5.99, p<$ 0.0001 ] , and lower still for neurons recorded from animals with longer training $\left(0.34 \pm 0.07 ; t\right.$ test: $\left.t_{(1,31)}=9.55, p<0.0001\right)$. Therefore, there was a significant shift toward paired-pulse depression, indicative of increased release probability.

To determine whether changes to sIPSC amplitude correlated with an improvement in behavioral performance, we examined two phases of the training period: the initial associative learning phase, during which animals continue to improve on the task procedure, and a latter phase, during which animals continued to train and learned to detect more-difficult stimuli. During the initial associative learning phase (Fig. $3 A$, left side), a measure of performance $\left(d^{\prime}\right)$ was correlated with sIPSC amplitude $\left(r^{2}=\right.$ $0.19, p<0.05)$. However, once animals reached asymptotic performance levels (i.e., when no further behavioral improvement was observed at the training stimulus, $100 \%$ amplitudemodulated depth), sIPSC amplitudes no longer correlated to behavioral performance (Fig. $3 A$, right side; $r^{2}=0.13, p=0.2$ ). A similar relationship between behavior and sIPSC amplitude was observed for neurons from appetitively trained animals (initial: $r^{2}=0.33, p<0.01$; asymptotic: $\left.r^{2}=0.11, p=0.28\right)$. We calculated sIPSC amplitude as a function of performance for each training regimen (Fig. $3 B$ ) and found that it was significantly smaller during the early stage of training for animals with a $d^{\prime}>$ 1.5. Figure $3 C$ shows that $P P R$ values do not differ as a function of performance.

\section{Discussion}

This study examined the premise that changes in cortical inhibitory synaptic function accompany the process of associative learning and improvement on an auditory detection task, independent of the training procedure. The primary finding was that sIPSC amplitudes became significantly smaller during the initial 
A

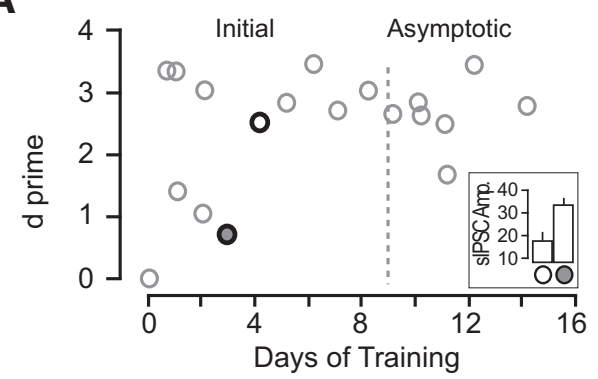

B

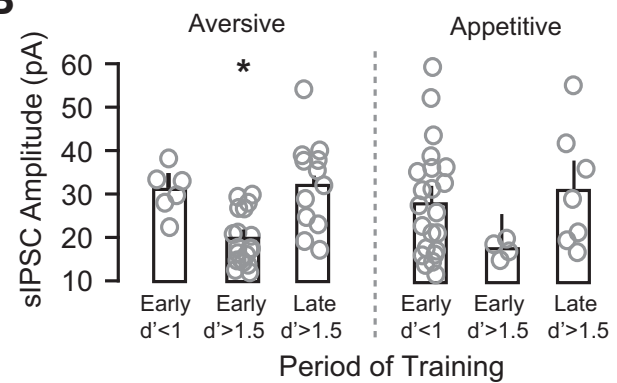

C

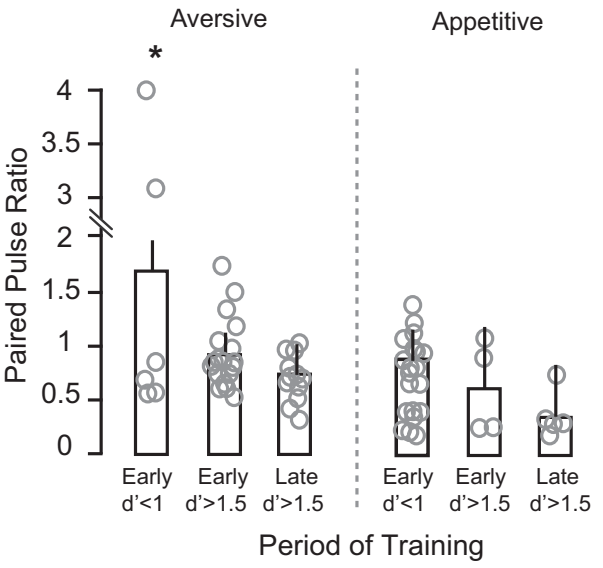

Figure 3. Initial associative learning is correlated with sIPSC amplitude. $\boldsymbol{A}, \boldsymbol{d}^{\prime}$ (d prime) for the trained stimulus of $100 \%$ amplitude-modulated depth is plotted as a function of days of training to show an initial sharp rise in the performance measure as animals form the initial association. This is followed by a period of asymptotic performance where performance on the easiest trained amplitude-modulated depth stimulus reaches asymptotic values. Vertical line illustrates this transition. Inset illustrates the SIPSC amplitudes obtained from two animals with similar amounts of training and widely different $d^{\prime}$ values (open circle, good learner; shaded circle, poor learner). $\boldsymbol{B}$, sIPSC amplitude is plotted as a function of training period and performance left to right: early $d^{\prime}<1$ (early in training when $d^{\prime}$ is $<1$ ); Early $d^{\prime}>1.5$ (early in training when $d^{\prime}$ is $>1.5$ ); late $d^{\prime}>1.5$ (late in training when $d^{\prime}$ is $>1.5$ ). This is plotted for both the aversive task (left) and the appetitive task (right). C, PPR is plotted as a function of training period and performance as displayed in $\boldsymbol{B}$. Error bars indicate SEM; ${ }^{*} p<0.05$.

phase of the associative learning for both aversive or appetitive training paradigms (Figs. $1 B, 2 B$ ). Moreover, during the initial learning processes of the associative learning, the magnitude of sIPSC degradation was correlated with the performance on the task (Figs. 3). Furthermore, after $\sim 10 \mathrm{~d}$ of training, the diminished inhibitory currents were gradually restored to control values. In contrast, the PPR was reduced both in trained and random presentation control animals. Together, these findings suggest that a transient decrease in inhibitory gain supports the alterations in stimulus processing that accompany learning.

Although there is no direct evidence linking spontaneous inhibitory events to learning, we have found that average sIPSC amplitude is a reliable proxy for evoked IPSC amplitude, as re- corded in auditory cortex pyramidal neurons (Kotak et al., 2008; Takesian et al., 2012; Mowery et al., 2014). Specifically, hearing loss-induced reduction in sIPSCs is mirrored by a reduction in fast-spiking (FS) interneuron-evoked IPSCs (Takesian et al., 2010). Therefore, our interpretation of the data is that the associative learning observed here coincides with a reduction in auditory cortex FS-evoked IPSCs. Our findings are consistent with those of earlier studies demonstrating that disinhibition is necessary and sufficient for simple auditory fear conditioning to occur. Fear conditioning is associated with the inhibition of parvalbuminpositive layer 2/3 interneurons (Letzkus et al., 2011) and interneurons within the amygdala (Wolff et al., 2014). Likewise, critical work in the primate auditory system demonstrates a general enhancement of excitability in cortex during the initial learning phases of a classical conditioning task, implying excitability as an outcome of the disinhibition (Blake et al., 2006). However, disinhibition is not unique to fear conditioning, having also been linked to motor learning (Smyth et al., 2010; Baarbé et al., 2014; Coxon et al., 2014). Our findings support the idea that reduced inhibition is a general cortical mechanism involved in many forms of associative learning.

While our findings do not demonstrate a causal relationship between changes to sIPSCs and auditory learning, they are consistent with a literature that links inhibitory strength to experiencedependent events or learning. For example, sIPSC frequency increases and tonic inhibitory currents decrease in somatosensory cortex following the pairing of vibrissae stimulation and tail shock (Tokarski et al., 2007; Urban-Ciecko et al., 2010). In the present study, by following the process of learning across several days of training, we demonstrated that diminished inhibitory strength occurred only in animals that also displayed auditory learning (i.e., poor learners and unpaired controls did not show reduced inhibition). The long-term impact of learning on cortical plasticity is not addressed by our findings since inhibitory strength returned to control levels during the course of training. In contrast, well trained animals display increased or decreased sound-driven responses during task engagement, depending on whether the training protocol is appetitive or aversive, respectively (David et al., 2012). Thus, the learning mechanisms that permit an initial sensory association to form may occur via a general transient reduction in inhibitory drive, but additional long-term changes in cortex function are associated with perceptual learning.

\section{Possible mechanisms of diminished inhibition during learning}

The reduction of sIPSC amplitude that accompanies the early stages of associative learning (Figs. $1 B, 2 B$ ) may reflect a postsynaptic change of $\mathrm{GABA}_{\mathrm{A}}$ receptor number or conductance. Conductance changes have been demonstrated to result from modification of subunit composition or phosphorylation state of the receptors, as well as change in the number of receptors at the postsynaptic membrane (Morishita and Sastry, 1996, Möhler, 2006). Reduction in $\mathrm{GABA}_{\mathrm{A}}$-mediated sIPSC amplitudes could also be reflective of a removal of $\mathrm{GABA}_{\mathrm{A}}$ receptors from the membrane at the onset of associative learning, as has been shown to occur at the onset of fear conditioning in the basolateral amygdala (Lin et al., 2009, 2011). Our results are also consistent with reduced sIPSC amplitudes displayed in a $\beta 3$ subunit knockout mouse model (Huntsman et al., 1994).

Reduction in the PPR in trained animals and controls exposed to random conditioned and unconditioned stimuli (Figs. 1C, 2C) suggest a $>50 \%$ increase in release probability. Therefore, pre- 
synaptic changes were associated with exposure to an environment in which animals presumably attempted to determine a contingency between conditioned and unconditioned stimuli, independent of associative learning. Short-term inhibitory depression can be attributed to several factors, including depletion of readily releasable vesicles, or activation of presynaptic $\mathrm{GABA}_{\mathrm{B}}$ receptors (Davies and Collingridge, 1993; Murthy et al., 2001; Zucker and Regehr, 2002; Takesian et al., 2010), and these mechanisms can display use-dependent changes (Mott et al., 1993; Murthy et al., 2001).

The suppression of inhibition may involve a disinhibitory circuit, including the activation of L1 GABAergic interneurons that suppress other inhibitory neurons (Letzkus et al., 2011; Pi et al., 2013). The learning-associated decrease in inhibitory gain is likely to involve cholinergic activity during training. When paired with sensory stimulation, stimulation of cholinergic nucleus basalis afferents to cortex induces long-lasting modifications to cortical response properties (Tremblay et al., 1990; Metherate and Ashe, 1992, 1993; Edeline et al., 1994; Kilgard and Merzenich, 1998 ) and is sufficient for memory formation and improved sensory perception (Miasnikov et al., 2008; Bieszczad et al., 2013; Froemke et al., 2013). In the present study, the greatest change in inhibitory synaptic function occurred during procedural learning of the auditory task (Figs. $1 B, 2 B$ ), suggesting that nucleus basalis activity could plausibly be involved in the long-term suppression of inhibition. Furthermore, the correlation between sIPSC amplitude and performance (Fig. 3) is consistent with the finding that the magnitude of nucleus basalis activation is correlated to performance (Weinberger et al., 2006).

A transient reduction of inhibition may permit the reorganization of receptive field properties necessary for learning the preferred amplitude-modulated stimulus in both the aversive and appetitive tasks. It is possible that decreased cortical inhibition may lead to heightened excitability, which would in turn contribute to learning-based plasticity. Finally, the return of baseline inhibitory function several days after initial training may restore the balance of cortical excitatory and inhibitory synapse function to the prelearning state, ending the period of heightened plasticity.

\section{References}

Baarbé J, Yielder P, Daligadu J, Behbahani H, Haavik H, Murphy B (2014) A novel protocol to investigate motor training-induced plasticity and sensorimotor integration in the cerebellum and motor cortex. J Neurophysiol 111:715-721. CrossRef Medline

Bao S, Chang EF, Woods J, Merzenich MM (2004) Temporal plasticity in the primary auditory cortex induced by operant perceptual learning. Nat Neurosci 7:974-981. CrossRef Medline

Bieszczad KM, Weinberger NM (2010) Representational gain in cortical area underlies increase of memory strength. Proc Natl Acad Sci U S A 107:3793-3798. CrossRef Medline

Bieszczad KM, Miasnikov AA, Weinberger NM (2013) Remodeling sensory cortical maps implants specific behavioral memory. Neuroscience 246: 40-51. CrossRef Medline

Blake DT, Strata F, Churchland AK, Merzenich MM (2002) Neural correlates of instrumental learning in primary auditory cortex. Proc Natl Acad Sci U S A 99:10114-10119. CrossRef Medline

Blake DT, Heiser MA, Caywood M, Merzenich MM (2006) Experiencedependent adult cortical plasticity requires cognitive association between sensation and reward. Neuron 52:371-381. CrossRef Medline

Brucato FH, Levin ED, Mott DD, Lewis DV, Wilson WA, Swartzwelder HS (1996) Hippocampal long-term potentiation and spatial learning in the rat: effects of GABAB receptor blockade. Neuroscience 74:331-339. CrossRef Medline

Buran BN, Sarro EC, Manno FA, Kang R, Caras ML, Sanes DH (2014) A sensitive period for the impact of hearing loss on auditory perception. J Neurosci 34:2276-2284. CrossRef Medline
Coxon JP, Peat NM, Byblow WD (2014) Primary motor cortex disinhibition during motor skill learning. J Neurophysiol 112:156-164. CrossRef Medline

David SV, Fritz JB, Shamma SA (2012) Task reward structure shapes rapid receptive field plasticity in auditory cortex. Proc Natl Acad Sci U S A 109:2144-2149. CrossRef Medline

Davies CH, Collingridge GL (1993) The physiological regulation of synaptic inhibition by GABAB autoreceptors in rat hippocampus. J Physiol 472: 245-265. CrossRef Medline

de Villers-Sidani E, Merzenich MM (2011) Lifelong plasticity in the rat auditory cortex: basic mechanisms and role of sensory experience. Prog Brain Res 191:119-131. CrossRef Medline

Dobrunz LE, Stevens CF (1997) Heterogeneity of release probability, facilitation, and depletion at central synapses. Neuron 18:995-1008. CrossRef Medline

Edeline JM, Pham P, Weinberger NM (1993) Rapid development of learning-induced receptive field plasticity in the auditory cortex. Behav Neurosci 107:539-551. CrossRef Medline

Edeline JM, Hars B, Maho C, Hennevin E (1994) Transient and prolonged facilitation of tone-evoked responses induced by basal forebrain stimulations in the rat auditory cortex. Exp Brain Res 97:373-386. Medline

Froemke RC, Carcea I, Barker AJ, Yuan K, Seybold BA, Martins AR, Zaika N, Bernstein H, Wachs M, Levis PA, Polley DB, Merzenich MM, Schreiner CE (2013) Long-term modification of cortical synapses improves sensory perception. Nat Neurosci 16:79-88. CrossRef Medline

Heffner HE, Heffner RS (1995) Conditioned avoidance. In: Methods in comparative psychoacoustics (Klump GM, Dooling RJ, Fay RR, Stebbins WC, eds). Basel: Academic.

Heffner HE, Koay G, Heffner RS (2006) Behavioral assessment of hearing in miceconditioned suppression. Curr Protoc Neurosci 8:8.21D. CrossRef Medline

Hsu KS, Ho WC, Huang CC, Tsai JJ (1999) Prior short-term synaptic disinhibition facilitates long-term potentiation and suppresses long-term depression at CA1 hippocampal synapses. Eur J Neurosci 11:4059-4069. CrossRef Medline

Huntsman MM, Isackson PJ, Jones EG (1994) Lamina-specific expression and activity-dependent regulation of seven GABAA receptor subunit mRNAs in monkey visual cortex. J Neurosci 14:2236-2259. Medline

Keeling MD, Calhoun BM, Krüger K, Polley DB, Schreiner CE (2008) Spectral integration plasticity in cat auditory cortex induced by perceptual training. Exp Brain Res 184:493-509. CrossRef Medline

Kelly JB, Cooke JE, Gilbride PC, Mitchell C, Zhang H (2006) Behavioral limits of auditory temporal resolution in the rat: amplitude modulation and duration discrimination. J Comp Psychol 120:98-105. CrossRef Medline

Keuroghlian AS, Knudsen EI (2007) Adaptive auditory plasticity in developing and adult animals. Prog Neurobiol 82:109-121. CrossRef Medline

Kilgard MP, Merzenich MM (1998) Cortical map reorganization enabled by nucleus basalis activity. Science 279:1714-1718. CrossRef Medline

Kotak VC, Takesian AE, Sanes DH (2008) Hearing loss prevents the maturation of GABAergic transmission in the auditory cortex. Cereb Cortex 18:2098-2108. CrossRef Medline

Letzkus JJ, Wolff SB, Meyer EM, Tovote P, Courtin J, Herry C, Lüthi A (2011) A disinhibitory microcircuit for associative fear learning in the auditory cortex. Nature 480:331-335. CrossRef Medline

Lin HC, Mao SC, Gean PW (2009) Block of gamma-aminobutyric acid-A receptor insertion in the amygdala impairs extinction of conditioned fear. Biol Psychiatry 66:665-673. CrossRef Medline

Lin HC, Tseng YC, Mao SC, Chen PS, Gean PW (2011) $\mathrm{GABA}_{\mathrm{A}}$ receptor endocytosis in the basolateral amygdala is critical to the reinstatement of fear memory measured by fear-potentiated startle. J Neurosci 31:88518861. CrossRef Medline

Manabe T, Wyllie DA, Perkel DJ, Nicoll RA (1993) Modulation of synaptic transmission and long-term potentiation: effects on paired-pulse facilitation and EPSC variance in the CA1 region of the hippocampus. J Neurophysiol 70:1451-1459. Medline

Metherate R, Ashe JH (1992) Nucleus basalis stimulation elicits neocortical activation and facilitates thalamocortical synaptic transmission: intracellular and extracellular recordings in rat auditory cortex. Soc Neurosci Abs 18:975.

Metherate R, Ashe JH (1993) Nucleus basalis stimulation facilitates thalamocortical synaptic transmission in the rat auditory cortex. Synapse 14:132-143. CrossRef Medline 
Miasnikov AA, Chen JC, Gross N, Poytress BS, Weinberger NM (2008) Motivationally neutral stimulation of the nucleus basalis induces specific behavioral memory. Neurobiol Learn Mem 90:125-137. CrossRef Medline

Mogil JS (1999) The genetic mediation of individual differences in sensitivity to pain and its inhibition. Proc Natl Acad Sci U S A 96:7744-7751. CrossRef Medline

Möhler H (2006) GABA(A) receptor diversity and pharmacology. Cell Tissue Res 326:505-516. CrossRef Medline

Molina-Luna K, Hertler B, Buitrago MM, Luft AR (2008) Motor learning transiently changes cortical somatotopy. Neuroimage 40:1748-1754. CrossRef Medline

Morishita W, Sastry BR (1996) Postsynaptic mechanisms underlying longterm depression of GABAergic transmission in neurons of the deep cerebellar nuclei. J Neurophysiol 76:59-68. Medline

Mott DD, Lewis DV (1991) Facilitation of the induction of long-term potentiation by GABAB receptors. Science 252:1718-1720. CrossRef Medline

Mott DD, Xie CW, Wilson WA, Swartzwelder HS, Lewis DV (1993) GABAB autoreceptors mediate activity-dependent disinhibition and enhance signal transmission in the dentate gyrus. J Neurophysiol 69:674-691. Medline

Mowery TM, Kotak VC, Sanes DH (2014) Transient hearing loss within a critical period causes persistent changes to cellular properties in adult auditory cortex. Cereb Cortex. Advance online publication. Retrieved March 16, 2015. Medline

Murthy VN, Schikorski T, Stevens CF, Zhu Y (2001) Inactivity produces increases in neurotransmitter release and synapse size. Neuron 32:673682. CrossRef Medline

Nielsen CS, Staud R, Price DD (2009) Individual differences in pain sensitivity: measurement, causation, and consequences. J Pain 10:231-237. CrossRef Medline

Ormond J, Woodin MA (2011) Disinhibition-mediated LTP in the hippocampus is synapse specific. Front Cell Neurosci 5:17. CrossRef Medline

Pi HJ, Hangya B, Kvitsiani D, Sanders JI, Huang ZJ, Kepecs A (2013) Cortical interneurons that specialize in disinhibitory control. Nature 503: 521-524. CrossRef Medline

Polley DB, Heiser MA, Blake DT, Schreiner CE, Merzenich MM (2004) Associative learning shapes the neural code for stimulus magnitude in primary auditory cortex. Proc Natl Acad Sci U S A 101:16351-16356. CrossRef Medline

Recanzone GH, Schreiner CE, Merzenich MM (1993) Plasticity in the frequency representation of primary auditory cortex following discrimination training in adult owl monkeys. J Neurosci 13:87-103. Medline

Reed A, Riley J, Carraway R, Carrasco A, Perez C, Jakkamsetti V, Kilgard MP (2011) Cortical map plasticity improves learning but is not necessary for improved performance. Neuron 70:121-131. CrossRef Medline

Rutkowski RG, Weinberger NM (2005) Encoding of learned importance of sound by magnitude of representational area in primary auditory cortex. Proc Natl Acad Sci U S A 102:13664-13669. CrossRef Medline

Sanes DH, Bao S (2009) Tuning up the developing auditory CNS. Curr Opin Neurobiol 19:188-199. CrossRef Medline
Sarro EC, Sanes DH (2010) Prolonged maturation of auditory perception and learning in gerbils. Dev Neurobiol 70:636-648. CrossRef Medline

Sarro EC, Sanes DH (2011) The cost and benefit of juvenile training on adult perceptual skill. J Neurosci 31:5383-5391. CrossRef Medline

Schreiner CE, Polley DB (2014) Auditory map plasticity: diversity in causes and consequences. Curr Opin Neurobiol 24:143-156. CrossRef Medline

Smyth C, Summers JJ, Garry MI (2010) Differences in motor learning success are associated with differences in M1 excitability. Hum Mov Sci 29:618-630. CrossRef Medline

Steward O, Tomasulo R, Levy WB (1990) Blockade of inhibition in a pathway with dual excitatory and inhibitory action unmasks a capability for LTP that is otherwise not expressed. Brain Res 516:292-300. CrossRef Medline

Swets JA (1973) The relative operating characteristic in psychology. Science 182:990-1000. Medline

Takahashi H, Funamizu A, Mitsumori Y, Kose H, Kanzaki R (2010) Progressive plasticity of auditory cortex during appetitive operant conditioning. Biosystems 101:37-41. CrossRef Medline

Takesian AE, Kotak VC, Sanes DH (2010) Presynaptic GABA ${ }_{B}$ receptors regulate experience-dependent development of inhibitory short-term plasticity. J Neurosci 30:2716-2727. CrossRef Medline

Takesian AE, Kotak VC, Sanes DH (2012) Age-dependent effect of hearing loss on cortical inhibitory synapse function. J Neurophysiol 107:937-947. CrossRef Medline

Tokarski K, Urban-Ciecko J, Kossut M, Hess G (2007) Sensory learninginduced enhancement of inhibitory synaptic transmission in the barrel cortex of the mouse. Eur J Neurosci 26:134-141. CrossRef Medline

Tremblay N, Warren RA, Dykes RW (1990) Electrophysiological studies of acetylcholine and the role of the basal forebrain in the somatosensory cortex of the cat. II. Cortical neurons excited by somatic stimuli. J Neurophysiol 64:1212-1222. Medline

Urban-Ciecko J, Kossut M, Mozrzymas JW (2010) Sensory learning differentially affects GABAergic tonic currents in excitatory neurons and fast spiking interneurons in layer 4 of mouse barrel cortex. J Neurophysiol 104:746-754. CrossRef Medline

Wasner GL, Brock JA (2008) Determinants of thermal pain thresholds in normal subjects. Clin Neurophysiol 119:2389-2395. CrossRef Medline

Weinberger NM, Miasnikov AA, Chen JC (2006) The level of cholinergic nucleus basalis activation controls the specificity of auditory associative memory. Neurobiol Learn Mem 86:270-285. CrossRef Medline

Wigström H, Gustafsson B (1986) Postsynaptic control of hippocampal long-term potentiation. J Physiol (Paris) 81:228-236. Medline

Wolff SB, Gründemann J, Tovote P, Krabbe S, Jacobson GA, Müller C, Herry C, Ehrlich I, Friedrich RW, Letzkus JJ, Lüthi A (2014) Amygdala interneuron subtypes control fear learning through disinhibition. Nature 509:453-458. CrossRef Medline

Yanz JL (1984) The application of the theory of signal detection to the assessment of speech perception. Ear Hear 5:64-71. CrossRef Medline

Yotsumoto Y, Watanabe T, Sasaki Y (2008) Different dynamics of performance and brain activation in the time course of perceptual learning. Neuron 57:827-833. CrossRef Medline

Zucker RS, Regehr WG (2002) Short-term synaptic plasticity. Annu Rev Physiol 64:355-405. CrossRef Medline 